\title{
Association between Serum Glutathione Peroxidases and Superoxide Dismutases mRNA Level with Coronary Artery Disease
}

\author{
Ali Reza Abaspour ${ }^{1}$, Mohammad Taghikhani'2, Mohamad Reza Parizade ${ }^{3}$, Mohsen Moohebati4, \\ Fahime Ghafoori' ${ }^{1}$, Mehraneh Mehramiz $^{3}$, Maryam Tayefi ${ }^{5}$, Amir Avan', Marzeye Ghalandari ${ }^{6}$, \\ Gordon A. A. Ferns ${ }^{7}$, Majid Ghayour-Mobarhan ${ }^{3,4,5^{*}}$
}

\begin{abstract}
${ }^{1}$ Department of Molecular Science, Faculty of Medicine, North Khorasan University of Medical Science, Bojnurd, Iran
${ }^{2}$ Department of Clinical Biochemistry, Tarbiat Modares University, Tehran, Iran

${ }^{3}$ Department of Biochemistry and Nutrition, Faculty of Medicine, Mashhad University of Medical Science (MUMS), Mashhad, Iran

${ }^{4}$ Cardiovascular Research Center, Avicenna Research Institute, Mashhad University of Medical Science (MUMS), Mashhad, Iran ${ }^{5}$ Department of Modern Sciences and Technologies, School of Medicine, Mashhad University of Medical Sciences, Mashhad, Iran ${ }^{6}$ Department of Biochemistry, Faculty of Basic Science, Payame Noor University, Mashhad, Iran

${ }^{7}$ Division of Medical Education, Brighton \& Sussex Medical School, Brighton, UK
\end{abstract}

Email: *ghayourm@mums.ac.ir

\begin{abstract}
How to cite this paper: Abaspour, A.R., Taghikhani, M., Parizade, M.R., Moohebati, M., Ghafoori, F., Mehramiz, M., Tayefi, M., Avan, A., Ghalandari, M., Ferns, G.A.A. and Ghayour-Mobarhan, M. (2017) Association between Serum Glutathione Peroxidases and Superoxide Dismutases mRNA Level with Coronary Artery Disease. Health, 9, 252-260.
\end{abstract}

https://doi.org/10.4236/health.2017.92017

Received: May 20, 2016

Accepted: February 12, 2017

Published: February 15, 2017

Copyright $\odot 2017$ by authors and Scientific Research Publishing Inc. This work is licensed under the Creative Commons Attribution International License (CC BY 4.0).

http://creativecommons.org/licenses/by/4.0/

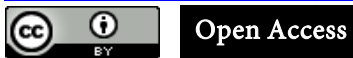

\begin{abstract}
Background: Oxidative stress plays a crucial role in the pathogenesis and progression of many diseases, including cardiovascular disease (CVD) and diabetes mellitus. Oxidative stress results from an imbalance between free radical formation and the protective antioxidant mechanisms. The latter mechanisms include superoxide dismutases (SODs) and glutathione peroxidases (GPx) that scavenge excessive ROS and protect cells against excess ROS production. The aim of current study was to determine the serum levels of SOD and serum GPx mRNA as well as the serum prooxidant-antioxidant balance in CVD patients. Method: A total of 103 subjects were recruited, with $\geq 50 \%$ stenosis $\left(\right.$ Angio $^{+}$) or $<50 \%$ stenosis of one or more coronary arteries by angiography $\left(\right.$ Angio $\left.^{-}\right)$. The expression levels of SOD and GPx in serum were measured using real time PCR. Biochemical-analyses (e.g., triglycerides; high-density lipoprotein cholesterol; low-density lipoprotein cholesterol; fasting-blood-glucose) were determined in all the subjects. Associations of SOD and GPx levels with biochemical and anthropometric characteristics were assessed together with evaluation of the serum pro-oxidant-antioxidant balance (PAB). Results: CVD subjects had a significantly higher level of fasting blood glucose (FBG), TC, LDL-C, TG and hs-CRP levels, as compared to control subjects. The level of serum $\mathrm{PAB}$ was significantly higher in the CVD group, $117.92 \pm 35.51$ and $110.65 \pm 27.65 \mu \mathrm{g} / \mathrm{dl}$ in the angio ${ }^{-}$and angio $^{+}$groups, respectively compared to
\end{abstract}


the control group $(54.26+23.25)$. Additionally we observed that the SOD-3 level was higher in angio ${ }^{+}$group versus control subjects. Conclusion: We have found that patients with CVD had a significantly higher prooxidantantioxidant and SOD-3 levels. Further studies in larger multi-center setting are warranted to explore the value of emerging biomarker in CVD patients.

\section{Keywords}

Coronary Artery Disease, Glutathione Peroxidases, Superoxide

Dismutases, Real Time PCR, Angiography

\section{Introduction}

Coronary artery disease (CVD) is the leading causes of death globally [1]. It is estimated that 17.3 million people died by CVD [2]. A growing body of studies have shown an association between oxidative stress and the development of CAD [3] [4]. The prooxidative/antioxidative cellular imbalance can induce excess oxidative stress [5] [6]. The human body defence against the cytotoxic effects of stress oxidative by biologic system provided by enzymatic and non-enzymatic mechanisms to recompense oxidative damage, including antioxidant enzymes, such as superoxide dismutases (SODs) and glutathione peroxidases (GPx) [7].

There are three isoforms of the SOD, cytosolic copper/zinc SOD $(\mathrm{Cu} / \mathrm{ZnSOD}$ or SOD1), mitochondrial manganese SOD (MnSOD or SOD2) and extracellular SOD (EC-SOD or SOD3). EC-SOD is responsible for $70 \%$ of the total SOD activity and found abundantly in the arterial wall that produced by vascular smooth muscle cells in normal physiologic conditions [8].

Among the members of the GPx family just GPx-3 has extracellular isoform. Plasma GPx-3, including antioxidant seleno-cysteine protein, catalyzes the reduction of hydrogen peroxide and lipid peroxides by glutathione. GPx-3 is a major defender of ROS produced during normal metabolism and even after stress [9].

Recently, a number of studies have pointed to the importance of the genetic determinants of CVD risk [10] [11]. Previous studies in our laboratory have revealed a relationship between decreased serum levels of extracellular isoforms of GPx and SOD activity in CAD patients [12]. Both enzymes are involved in the redox status, and over-expression of these ROS eliminating enzymes leads to diminished oxidative stress; thus they have been the subject of many clinical investigations. These enzymes decrease in complicated atherosclerotic plaques; thereby, GPx and SOD could be considered as a potential diagnostic marker. Thus we designed a study to evaluate the association of serum GPx3, SOD1 and SOD3 mRNA in coronary artery disease.

\section{Methods and Subjects}

\subsection{Population}

62 patients (30 males and 32 females) and 41 age and sex adjusted healthy vo- 
lunteers (20 males and 21 females) were recruited from Ghaem Medical Education Hospital Mashhad, Iran. The presence of stenoses $\geq 50 \%$ in at least one major coronary artery was assessed using angiographic assessment. Coronary angiograms were performed using routine procedures [13]. Anthropometric parameters were measured. The study was reviewed and approved by the Ethic Committee of Tarbyat Modares University and informed consent was obtained from all participants.

\subsection{Collection of Serum Samples and Measurement of Lipids and Lipoproteins}

Biochemical analysis including fasting triglycerides, total cholesterol, lowdensity lipoprotein cholesterol (LDL-C), and high-density lipoprotein cholesterol (HDL-C) was determined.

\subsection{Oxidative Stress Assays}

Prooxidant-antioxidant balance $(\mathrm{PAB})$ assay was used as described previously [14].

\subsection{RNA Extraction, cDNA Synthesis and Real-Time RT-PCR}

RNAs was extracted by QIAamp Circulating Nucleic Acid Kit (Qiagen, Hilden, Germany) according to the manufacturer's Instructions. The RNA concentration was measured by measuring UV light absorbance at $260 \mathrm{~nm}$ with nanodrop. cDNA synthesis was carried out by RT (reverse transcription) using Quanti Tect Reverse Transcription Kit (Qiagen, Germany).

cDNA was amplified with real-time PCR using the RotorGene system (Qiagen, Hilden, Germany), with SYBR green master mixed (Takara, Jepan). The primers for GAPDH, GPx3, and SOD1 were designed by Gene Runner (Table $1)$.

Real-time PCR reactions consisted of denaturation at $95^{\circ} \mathrm{C}$ for $4 \mathrm{~min}$, annealing/extension at $60^{\circ} \mathrm{C}$ for $35 \mathrm{~s}$, by 40 cycles. The final extension was at $72^{\circ} \mathrm{C}$ for

Table 1. Primers used for amplification.

\begin{tabular}{ccc}
\hline Gene & Forward/rivers & Primer \\
\hline GAPDH & $\mathrm{F}$ & 5'-GACAACAGCCTCAAGATCATCAG-3' \\
GAPDH & $\mathrm{R}$ & 5'-ATGGCATGGACTGTGGTCATGAG-3' \\
GPx3 & $\mathrm{F}$ & 5'-AAACAGGAGCCAGGCGAGAACT-3' \\
GPx3 & $\mathrm{R}$ & 5'-CCCGTTCACATCTCCTTTCTCAAA-3' \\
SOD3 & $\mathrm{F}$ & 5'-GTGTCCCAAGACAATC-3' \\
SOD3 & $\mathrm{R}$ & 5'-GTGCTATGGGGACAGG-3' \\
SOD1 & $\mathrm{F}$ & 5'-CCACTCTGAGGTCTCACCTT-3' \\
SOD1 & $\mathrm{R}$ & 5'-ATGGTGGGTCTCGGTATAGG-3'
\end{tabular}

GAPDH: glyceraldehyde-3-phosphate dehydrogenase, GPx: glutathione peroxidases, SOD: superoxide dismutases, F: forward primer, R: reverse primer. 
$5 \mathrm{~min}$. The $2^{\Delta \Delta \mathrm{Ct}}$ formula for GPX and SOD: $2^{\text {(CT target-CTGAPDH)patients-(CT target-CT }}$ GAPDH)controls was used to determine differences in GPX and SOD genes expression [15].

\subsection{Statistical Analysis}

All statistical analyses were performed using the SPSS 16 (SPSS Inc., Chicago, IL, USA). Descriptive statistics including mean \pm standard deviation (SD) were determined for variables with normally distribution or data were expressed as median \pm Inter Quartile Range (IQR) for not normally distributed variables. For normally distributed variables, $t$-student test was used, while Bonferroni correction was considered for multiple comparisons. The Mann-Whitney $U$ test was used for continuous variables. For categorical parameters, Chi-square or Fisher exact tests were used. A two-sided $P$ value $<0.05$ was considered statistically significant.

\section{Results}

As shown in Table 2, we found a significant difference for waist circumference,

Table 2. Demographic and clinical characteristics of population.

\begin{tabular}{cccc}
\hline & Angio $^{+}$ & Angio $^{-}$ & Control \\
\hline Number of subjects & 36 & 26 & 41 \\
Gender (F/M) & $19 / 17$ & $13 / 13$ & $21 / 20$ \\
Age (year) & $60.6 \pm 10.7$ & $58.8 \pm 9.9$ & $59.6 \pm 10.6$ \\
Height (cm) & $160.25 \pm 9.28$ & $162.04 \pm 8.78$ & $161.68 \pm 7.94$ \\
Weight (kg) & $71.19 \pm 11.68$ & $69.73 \pm 13$ & $67.97 \pm 11.97$ \\
BMI & $27.85 \pm 4.77$ & $26.53 \pm 4.66$ & $25.96 \pm 3.8$ \\
Waist circumference (cm) & $93.36 \pm 11.48$ & $92.77 \pm 13.53$ & $86.05 \pm 12.17^{\mathrm{g}}$ \\
Hip circumference (cm) & $93.58 \pm 9.7$ & $93.50 \pm 13.05$ & $91.61 \pm 10.5$ \\
Waist/hip ratio & $0.996 \pm 0.05^{\mathrm{c}}$ & $0.992 \pm 0.06^{\mathrm{b}}$ & $0.938 \pm 0.08^{\mathrm{i}}$ \\
SBP (mmHg) & $138.47 \pm 16.25^{\mathrm{b}}$ & $131.92 \pm 17.27$ & $125.53 \pm 14.08^{\mathrm{h}}$ \\
DBP (mmHg) & $79.31 \pm 9.79^{\mathrm{c}}$ & $78.27 \pm 11.04^{\mathrm{b}}$ & $71.05 \pm 7.98^{\mathrm{i}}$ \\
FBG (mg/dl) & $135.92 \pm 74.68^{\mathrm{b}}$ & $115.04 \pm 64.46$ & $96.79 \pm 14.9^{\mathrm{g}}$ \\
TC (mg/dl) & $182.56 \pm 38.12^{\mathrm{a}}$ & $159.77 \pm 37.11^{\mathrm{a}}$ & $158.74 \pm 35.91^{\mathrm{g}}$ \\
LDL-C (mg/dl) & $113.08 \pm 31.27^{\mathrm{a}, \mathrm{e}}$ & $90.19 \pm 31.54$ & $92.13 \pm 28.28^{\mathrm{h}}$ \\
HDL-C (mg/dl) & $42.83 \pm 6.96$ & $41.65 \pm 16.67$ & $39.37 \pm 8.08$ \\
TG (mg/dl) & $132.50 \pm 54.02^{\mathrm{a}}$ & $141.81 \pm 68.29^{\mathrm{b}}$ & $102.32 \pm 34.95^{\mathrm{h}}$ \\
hs-CRP (mg/l) & $10.34 \pm 17.70$ & $8.98 \pm 12.44$ & $4.68 \pm 7.17$ \\
PAB & $117.92 \pm 35.51$ & $110.65 \pm 27.65$ & $54.26 \pm 23.25$ \\
\hline
\end{tabular}

Values are presented as mean $\pm \mathrm{SD}$. $B M I$ body mass index, $S B P$ systolic blood pressure, $D B P$ diastolic blood pressure, $F B G$ fasting blood glucose, TC total cholesterol, $L D L-C$ low-density lipoprotein cholesterol, $H D L$ - $C$ high-density lipoprotein cholesterol, $T G$ triglycerides, $h s-C R P$ high-sensitivity C-reactive protein, $\mathrm{PAB}$ pro-oxidant anti-oxidant balance. Compared with the control group: ${ }^{\mathrm{a}} p<0.05,{ }^{\mathrm{b}} p<0.01,{ }^{\mathrm{c}} p<0.001$; compared with the Angio ${ }^{-}$group: ${ }^{\mathrm{d}} p<0.05$, ${ }^{\mathrm{e}} p<0.01,{ }^{\mathrm{f}} p<0.001$; comparison between all groups: ${ }^{\mathrm{g}} p<0.05$, ${ }^{\mathrm{h}} p<0.01,{ }^{\mathrm{i}} p<0.001$ 
waist/hip ratio, systolic blood pressure and diastolic blood pressure $(p<0.05)$ between the groups. Not surprisingly no significant differences were detected in FBS, TC, TG and LDL-C between the groups $(p<0.05)$. The Angio ${ }^{+}$patients had a significantly higher serum levels of TC and LDL-C compared with Angio ${ }^{-}(p<$ $0.05)$ and control groups $(p<0.05)$. Finally, no significant difference was observed in HDL-C level among the three groups $(p>0.05)$. Demographic and clinical characteristics of the subjects are summarized in (Table 2).

The intra-assay coefficient of variation (CV) for the quantitation of GAPDH, GPX3, SOD1 and SOD3 mRNA expression were 3.17\%, 3.94\%, 3.11\% and 3.81\% respectively. The inter-assay coefficient of variation (CV) for GAPDH was $6.3 \%$, $9.2 \%, 5.6 \%$ and $9.3 \%$ respectively. There was no significant difference in serum PAB between the Angio $^{+}$and Angio $^{-}$groups $(p>0.05)$, while there was a significant difference in serum $\mathrm{PAB}$ between two patient groups with normal group ( $p$ $<0.001$ ) (Figure 1 and Figure 2). Gene expression analyses showed that the expression levels of $G P \times 3, S O D 1$ and $S O D 3$ genes were increased in patient groups.

\section{Discussion}

We have found that the serum levels of GPx and SOD were elevated in CVD patients with angiographic evidence of coronary artery stenosis.

Excess oxidative stress is an important step in the development of atherosclerosis. Hydrogen peroxide, superoxide and hydroxyl radicals have direct cytotoxic effects, induce endothelial dysfunction and apoptosis of vascular smooth muscle

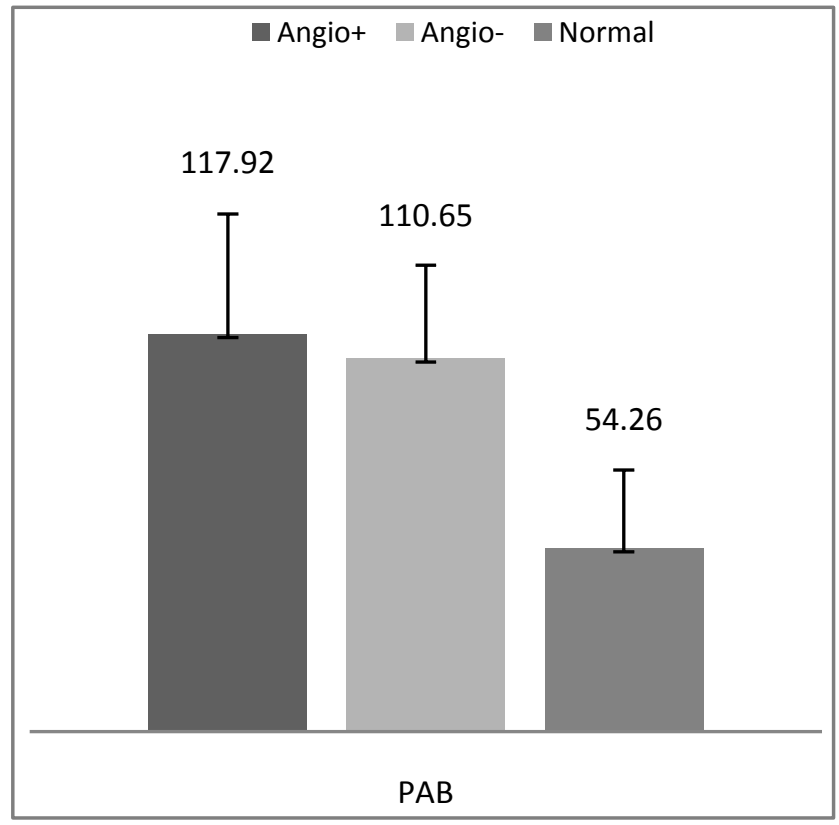

Figure 1. Serum pro-oxidant anti-oxidant balance (PAB) in relation to the CAD. Angio ${ }^{+}$: the presence of one or more stenoses $\geq$ $50 \%$ in diameter of at least one major coronary, Angio ${ }^{-}$: the presence of one or no stenoses $\geq 50 \%$ in diameter of at least one major coronary artery $\mathrm{PAB}$ : pro-oxidant anti-oxidant balance. 


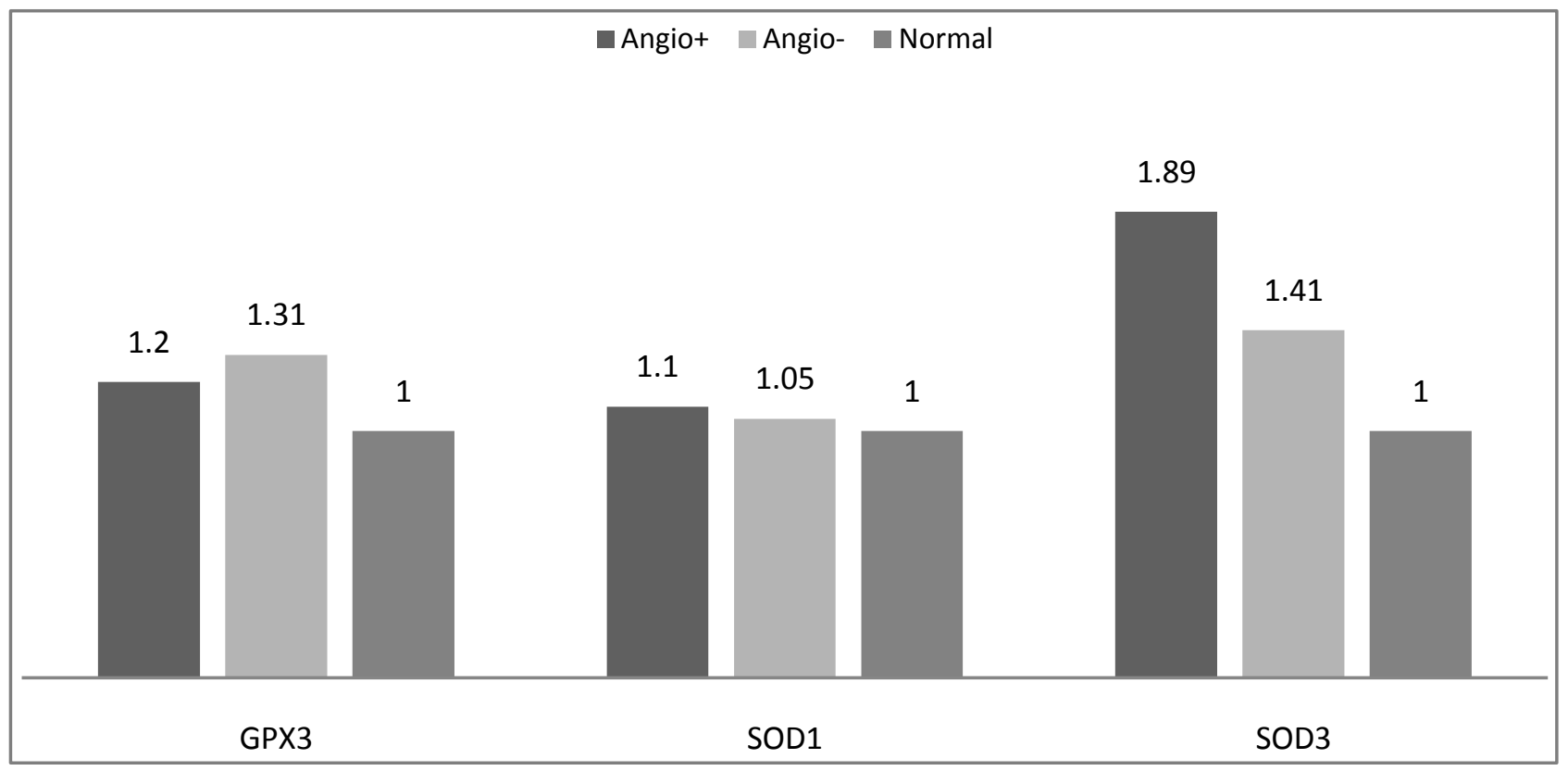

Figure 2. Serum GPx3, SOD1 and SOD3 mRNA level in relation to the CAD. Angio ${ }^{+}$: the presence of one or more stenoses $\geq 50 \%$ in diameter of at least one major coronary, Angio ${ }^{-}$: the presence of one or less stenoses $\geq 50 \%$ in diameter of at least one major coronary artery GPx3: glutathione peroxidases 3, SOD1: superoxide dismutases 1, SOD3: superoxide dismutases 3.

cells and lead to the destabilization of atherosclerotic plaques [14]. GPx and SOD form essential cellular mechanisms to scavenge ROS in the vessel wall [16]. Several studies have been revealed association between decreased serum activity of ROS-inactivating enzymes; SOD and GPx in CAD patients. Emerging evidence has focused on SOD and GPx due to their fundamental role in control of cellular homeostasis and redox condition in response to internal and external stimulants [17]. A number of lines of evidence suggest that an altered oxidantantioxidant imbalance is associated with CAD [15]. Other studies have also revealed an elevated oxidative stress and reduce of plasma SOD and GPx in CAD patients [18] [19]. Moreover, several studies have demonstrated that GPx-3 deficiency has been associated with cardiovascular disease [20] [21], although its role in transcriptional level remained unknown [10]. Of note the role of oxidative stress and variations in the intracellular redox states as modulators of the transcription of numerous genes [22], such as GPx-3 and SOD [23]. The association between decreased GPx-3 activity and the development of ischemic stroke [24] and CAD [25] indicates the importance of this enzyme for homeostasis of vascular functions. However, a number of controversies have developed regarding the role of plasma GPx-3 as an antioxidant enzyme in plasma due to the relatively low serum GSH.

Thioredoxin and glutaredoxin have been recognized as electron donors for GPx-3 [26]. It is appeared that the selenium (Se) in selenoproteins such as in $\mathrm{GPx}$, is a key component required for normal health. Ghayour et al. have reported the higher risk of cardiovascular disease in individuals with low serum selenium [12]. Moreover regulation of selenoproteins is special that their translation machinery enables antermination codon (UGA) to be coded for seleno- 
cysteine. It would be appeared that several translational cofactors have been necessary for biosynthesis of these proteins [27]. We have found that serum GPx and SOD mRNA is not associate with known coronary risk factors, while serum GPx and SOD mRNA level was elevated in individuals with established coronary stenosis.

\section{Grant}

This study was support by grant from Mashhad University of Medical Sciences.

\section{Conflict of Interest}

The authors have no conflict of interest to disclose.

\section{References}

[1] (2011) Global Status Report on Noncommunicable Disaeses 2010. World Health Organization, Geneva.

[2] (2011) Global Atlas on Cardiovascular Disease Prevention and Control. World Health Organization, Geneva.

[3] Paoletti, R., Gotto, A.M. and Hajjar, D.P. (2004) Inflammation in Atherosclerosis and Implications for Therapy. Circulation, 109, 20-26. https://doi.org/10.1161/01.CIR.0000131514.71167.2e

[4] Martinet, W., Knaapen, M.W., De Meyer, G.R., Herman, A.G. and Kockx, M.M. (2002) Elevated Levels of Oxidative DNA Damage and DNA Repair Enzymes in Human Atherosclerotic Plaques. Circulation, 106, 927-932. https://doi.org/10.1161/01.CIR.0000026393.47805.21

[5] Papaharalambus, C.A. and Griendling, K.K. (2007) Basic Mechanisms of Oxidative Stress and Reactive Oxygen Species in Cardiovascular Injury. Trends in Cardiovascular Medicine, 17, 48-54. https://doi.org/10.1016/j.tcm.2006.11.005

[6] Halliwell, B. and Gutteridge, J.M.C. (1999) Free Radicals in Biology and Medicine. 3rd Edition, Oxford Science Publications, Oxford.

[7] Heistad, D.D. (2006) Oxidative Stress and Vascular Disease: 2005 Duff Lecture. Arteriosclerosis, Thrombosis, and Vascular Biology, 26, 689-695. https://doi.org/10.1161/01.ATV.0000203525.62147.28

[8] Zelko, I.N., Mariani, T.J. and Folz, R.J. (2002) Superoxide Dismutase Multigen Family: A Comparison of the CuZn-SOD (SOD1), Mn-SOD (SOD2), and Ec-SOD (SOD3) Gene Structures, Evolution, and Expression. Free Radical Biology \& Medicine, 33, 337-349. https://doi.org/10.1016/S0891-5849(02)00905-X

[9] Bierl, C., Voetsch, B., Jin, R.C., Handy, D.E. and Loscalzo, J. (2004) Determinants of Human Plasma Glutathione Peroxidase (GPx-3) Expression. Journal of Biological Chemistry, 279, 26839-26845. https://doi.org/10.1074/jbc.M401907200

[10] McPherson, R. (2010) Chromosome 9p21 and Coronary Artery Disease. New England Journal of Medicine, 362, 1736-1737. https://doi.org/10.1056/NEJMcibr1002359

[11] Roberts, R., Stewart, A.F., Wells, G.A., Williams, K.A., Kavaslar, N. and McPherson, R. (2007) Identifying Genes for Coronary Artery Disease: An Idea Whose Time Has Come. Canadian Journal of Cardiology, 23, 7A-15A. https://doi.org/10.1016/S0828-282X(07)71000-0

[12] Ghayour-Mobarhan, M., Lamb, D.J., Taylor, A., et al. (2005) Effect of Statin Thera- 
py on Serum Trace Element Status in Dyslipidaemic Subjects. Journal of Trace Elements in Medicine and Biology, 19, 61-67.

https://doi.org/10.1016/j.jtemb.2005.06.003

[13] HamidiAlamdari, D., Ghayour-Mobarhan, M., Tavallaie, S., Parizadeh, S.M.R., Moohebati, M. and Ghafoori, F. (2008) Prooxidant-Antioxidant Balance as a New Risk Factor in Patients with Angiographically Defined Coronary Artery Disease. Clinical Biochemistry, 41, 375-380.

https://doi.org/10.1016/j.clinbiochem.2007.12.008

[14] Galkina, E. and Ley, K. (2009) Immune and Inflammatory Mechanisms of Atherosclerosis. Annual Review of Immunology, 27, 165-197.

https://doi.org/10.1146/annurev.immunol.021908.132620

[15] Kenneth, J., Livak, A. and Thomas, D. (2001) Schmittgen Analysis of Relative Gene Expression Data Using Real-Time Quantitative PCR and the 2- $\Delta \mathrm{C}$ t Method. $\mathrm{Me}$ thods, 25, 402-408. https://doi.org/10.1006/meth.2001.1262

[16] Strehlow, K., Rotter, S., Wassmann, S., Adam, O., Grohé, C., Laufs, K., Böhm, M. and Nickenig, G. (2003) Modulation of Antioxidant Enzyme Expression and Function by Estrogen. Circulation Research, 93, 170-177.

https://doi.org/10.1161/01.RES.0000082334.17947.11

[17] Ghayour-Mobarhan, M., Taylor, A., Lanham-New, S., Lamb, D., AzimiNezhad, M., Kazemi-Bajestani, M.R., Ghafouri, F., Livingstone, C., Wang, T. and Ferns, G.A. (2008) Serum Selenium and Glutathione Peroxidase in Patients with Obesity and Metabolic Syndrome. Pakistan Journal of Nutrition, 7, 112-117. https://doi.org/10.3923/pjn.2008.112.117

[18] Kaya, Y., Çebi, A., Söylemez, N., Demir, H., Hakan, H. and Bakan, E. (2012) Correlations between Oxidative DNA Damage, Oxidative Stress and Coenzyme Q10 in Patients with Coronary Artery Disease. International Journal of Medical Sciences, 9 , 621-626. https://doi.org/10.7150/ijms.4768

[19] Khaki-khatibi, F., Yaghoubi, A.R. and Rahbani, N.M. (2012) Study of Antioxidant Enzymes, Lipid Peroxidation, Lipid Profile and Immunologic Factor in Coronary Artery Disease in East Azarbijan. International Journal of Biological and Medical Research, 1, 147-152. https://doi.org/10.14194/ijmbr.1210

[20] Zelko, I.N. (2002) Superoxide Dismutase Multigene Family. Free Radical Biology \& Medicine, 33, 337-349. https://doi.org/10.1016/S0891-5849(02)00905-X

[21] Fujita, H., Fujishima, H., Chida, S., Takahashi, K., Qi, Z., Kanetsuna, Y., Breyer, M.D., Harris, R.C., Yamada, Y. and Takahashi, T. (2009) Reduction of Renal Superoxide Dismutase in Progressive Diabetic Nephropathy. Journal of the American Society of Nephrology, 20, 1303-1313. https://doi.org/10.1681/ASN.2008080844

[22] AllenR, G. and Tresini, M. (2000) Oxidative Stress and Gene Regulation. Free Radical Biology \& Medicine, 28, 463-499. https://doi.org/10.1016/S0891-5849(99)00242-7

[23] Valko, M., Rhodes, C.J., Moncol, J., Izakovic, M. and Mazur, M. (2006) Free Radicals, Metals and Antioxidants in Oxidative Stress-Induced Cancer. Chemico-Biological Interactions, 160, 1-40. https://doi.org/10.1016/j.cbi.2005.12.009

[24] Voetsch, B., Jin, R.C., Bierl, C., Deus-Silva, L., Camargo, E.C.S., Annichino-Bizacchi, J.M. and Handy, D.E. (2008) Role of Promoter Polymorphisms in the Plasma Glutathione Peroxidase (GPx-3) Gene as a Risk Factor for Cerebral Venous Thrombosis. Stroke, 39, 303-307. https://doi.org/10.1161/STROKEAHA.107.490094

[25] Leopold, J.A. and Loscalzo, J. (2005) Oxidative Enzymopathies and Vascular Disease. Arteriosclerosis, Thrombosis, and Vascular Biology, 25, 1332-1340. https://doi.org/10.1161/01.ATV.0000163846.51473.09 
[26] Maiorino, M., Ursini, F., Bosello, V., Toppo, S., Tosatto, S.C.E., Mauri, P., Becker, K., Roveri, A., Bulato, C., Benazzi, L., De Palma, A. and Flohé, L. (2007) The Thioredoxin Specificity of Drosophila GPx: A Paradigm for a Peroxiredoxin-Like Mechanism of Many Glutathione Peroxidases. Journal of Molecular Biology, 365, 1033-1046. https://doi.org/10.1016/j.jmb.2006.10.033

[27] Alexandre, A., Sotiria, P. and Dieter, S. (2007) Natural Expansion of the Genetic Code. Nature Chemical Biology, 3, 29-35. https://doi.org/10.1038/nchembio847

Submit or recommend next manuscript to SCIRP and we will provide best service for you:

Accepting pre-submission inquiries through Email, Facebook, LinkedIn, Twitter, etc. A wide selection of journals (inclusive of 9 subjects, more than 200 journals) Providing 24-hour high-quality service User-friendly online submission system Fair and swift peer-review system Efficient typesetting and proofreading procedure Display of the result of downloads and visits, as well as the number of cited articles Maximum dissemination of your research work

Submit your manuscript at: http://papersubmission.scirp.org/

Or contact health@scirp.org 